\title{
Forming and Norming Social Media Adoption in the Corporate Sector
}

\author{
Ines Mergel \\ Maxwell School of Citizenship and \\ Public Affairs \\ Syracuse University \\ 215 Eggers Hall, Syracuse NY \\ 13244 \\ 001-315-443-5100 \\ iamergel@maxwell.syr.edu
}

\author{
Gabriel Mugar \\ The School of Information Studies \\ Syracuse University \\ 337 Hinds Hall, Syracuse NY \\ 13244 \\ 001-315-443-5504
}

gmugar@syr.edu

\author{
Mohammad Hossein Jarrahi \\ The School of Information Studies \\ Syracuse University \\ 337 Hinds Hall, Syracuse NY \\ 13244 \\ 001-315-443-5504 \\ mhjarrah@syr.edu
}

\begin{abstract}
Social media increasingly pervade the business context. Despite the widespread fascination with the transformative capabilities of these tools, and an increased observability of online social media practices in the corporate sector, the adoption process at the organizational level as well as its consequences on policies and strategies are currently less understood. To ameliorate this gap, this study sets out to examine adoption patterns and their resulting organizational policies and strategies that influence or are influenced by specific adoption behaviors. In doing so, this study builds on findings of an interpretive case analysis, that integrates insights from various social media strategists, purposively selected from multiple industries. Guided by several technology adoption frameworks - primarily Orlikowski's structurational analysis - three distinct pathways of social media adoption emerged from the data: (1) early adopters, (2) internal mavericks and (3) bandwagon jumpers. Each pathway is driven by either internal or external social behaviors, and leads to distinct organizational social media practices. Our data shows that existing organizational polices and norms mediate social media adoption practices while in turn, innovative adoption practices transform and influence the emergence of policies and norms in the form of a reflexive feedback mechanism.
\end{abstract}

\section{Categories and Subject Descriptors}

K.4.3 [Computers and Society]: Organizational Impacts computer-supported collaborative work.

\section{General Terms}

Management, Human Factors and Theory.

\section{Keywords}

Social media, Adoption of innovation, Standardization of use, Structuration, Corporate sector

\section{INTRODUCTION}

Understanding the role of social media in the corporate context has become increasingly important over the past few years. According to a recent report by the Pew Internet and American Life Project, the number of adults using social media technology has increased from $8 \%$ in 2005 to $65 \%$ in 2011 [17]. These numbers illustrate the urgency for corporations to begin integrating social media into their communication practice of interfacing with current and potential customers. So far, the corporate sector is slower in adopting social media practices than other sectors, such as higher education [4; 12]. Nonetheless, social media have transformed from a personal communication tool for youth into a vehicle through which firms can revolutionize their interactions with their stakeholders including their customers and employees. Social media tools are designed to enable their users to shift one-way broadcasting of information to reciprocal interactions $[18 ; 21]$. In its recent report, Forrester research notes that nearly half of all firms are now investing in social tools in their organization [15]. Along the same line, a study of Fortune 500 corporations concludes that in the year $2010,60 \%$ of these companies had corporate Twitter accounts, and $56 \%$ ran corporate profiles on Facebook [3]. These figures clearly highlight the growing importance of social media in the corporate sector. As George notes: "social networking is the most significant business development of 2010." [10]

Studying the adoption at the micro-level, a budding stream of research within the fields of information studies has recently emerged. Several empirical studies have investigated how specific tools are adopted by individual users in the workplace [e.g., 7; 15; $24 ; 26 ; 27]$. This literature, however, is typically oriented to individual-level or group-level perspectives. As a result, presently there is little understanding about the social media adoption process at the organizational level. Beyond the macrolevel analyses and micro-level examinations, we require empirical studies at the meso-level in order to arrive at a detailed and rich picture of social media adoption in the corporate sector. To do so, a focus at the organizational level is needed to understand the impact of organizational norms, policies, strategies and practices that shape adoption strategies. The perceptions of social media strategists who play an integral role in the day-to-day practices, but also co-write organization-wide social media strategies help to form an understanding beyond the observable social media practices, and allow us to understand why and how social media use impacts the organization as a whole. Therefore our study aims to answer the following research questions: 
Research Question 1: How do organizations adopt social media practices?

Research Question 2: What pathways of social media use can be identified?

Research Question 3: How do organizations integrate emergent social media practices into their organizational structure and institutional norms?

\section{UNDERSTANDING SOCIAL MEDIA ADOPTION}

We frame our analysis of corporate adoption of social media technology by looking to theorists who view institutional forms as a moment in the ongoing dialectical relationship between structure and agency $[6 ; 11]$. Using this framework for understanding the dialectical constitution of institutional form, we concern ourselves with the process of how normative structures of institutions, the attitudes of adopters, and the features of the technology itself combine to create new norms and practices within the institution and how this impacts the institution going forward. We begin by looking to Desanctis' and Poole's [8] use of Adaptive Structuration Theory to analyze the adoption of Decision Support Systems (DSS) in corporations. This framework, grounded in Giddens [11] and Bourdieu's [6] dialectical analysis of institutional form, treats the emergent practices of technology use as a result of the interplay between institutional norms and the social characteristics of technology. Social characteristics of technology can be understood, for example, as the restrictive characteristics of the technology, or the features that allow or do not allow a user to perform tasks in a specific context. The authors also look at what they call the "spirit" of the technology, or what values the technology represents and what goals it supports. In addition to examining the role of the institutional norms in emergent practice, the authors point to organizational culture (non-normative) as being of critical importance in the analysis. The example used by the authors of organizational culture is attitudes towards technology in general. The authors break this into three aspects: 1) Confidence in use of existing technology, 2) perceived value of technology to the organization, 3) willingness to master new technology. For the authors, the outcome of the interplay between the social structure of the technology and the institutional/cultural norms of the organization results in a redefinition of the institutional form that adheres to how the new technology has impacted the way people work.

Desanctis and Poole provide a valuable framework for the analysis of how new technology can impact the institutional norms of an organization. For the purpose of this analysis, we are also interested in using their work to gain a detailed conceptual description of the components that deserve attention in the analysis, namely the technology and both the normative and nonnormative structure of the organization. To inform our broader framework for analysis, we turn to Orlikowski's practice lens for the study of technology in organization [22]. Similar to Desanctis and Poole but using a less dialectical lens, Orlikowski views the social structuring potential of technology as not being identifiable in the technology itself, but appearing only when the technology is viewed in practice. While Desanctis and Poole treat the relationship between technology and social norms in a dialectical fashion, where we can identify both the norms and the characteristics independent of the context in which they engage,
Orlikowski puts her emphasis on the social context of the users and lets the characteristics of the technology emerge through the filter of norms that determine how the technology is practiced. Orlikowski notes that this view of technology is not an ontological one, meaning she does not deny that an artifact has social characteristics inscribed in it, rather it is an analytical one, meaning that these social characteristics can only be understood in context, through their emergent practice. Orlikowski provides the example of her analysis through the example of people using tax preparation software. She notes that when people use this software on a regular basis, they "draw on its inscribed properties and embedded information content, their own experiences with technology, as well as their understanding of their rights and obligations as tax payers, to enact a set of tax reporting rules and resources with the software" [22, p.8].

Since the introduction of the practice lens, the model has been used in full or referenced in the analysis of technology use and adoption studies extensively. Recent examples of Orlikowski's practice lens model include the analysis of adoption processes for decision support systems [16], course management systems (CMS) [13], and clinical information systems [23]. In all of these examples, the practice lens was used to offer a new perspective to the discussion of how these technologies are used and adopted in the respective contexts of the studies. Mackrell et al. [16] used the practice lens to analyze the reasons behind the minimal adoption of decision support systems in the Australian cotton industry. The goal for using the practice lens was to gain a more subjective understanding of how the farmers where reacting to the new technology, how it impacted their practices, and how the technology was ultimately used. Similarly, Jarrahi [13] used the practice lens to examine the various institutional and interpretive conditions that impacted the ways that different professors used a CMS. For example, the model brought attention to the interpretive frame of the workplace as it appeared in the shared meanings between professors on what the CMS meant to them in terms of how they were used. For Rodriguez and Pozzebon [23], the model was used in combination with other frameworks to gain more insight into the power struggles that ensued in administrative offices during the implementation of clinical information systems. Amongst other frameworks, the practice lens was used to help the authors understand how the day-to-day use of the technology and decisions around adoption were influenced via the interpretive frame of the stakeholders at the hospital.

The three elements described in the above example represent what Orlikowski sees as the three conditions that impact the emergent properties of the technological practice in an organization: interpretive, technological, and institutional. The interpretive condition looks at the conventions of the workplace and the assumptions and expectations of users about the technology what is often referred to as acceptable technology use. The technological conditions consider the properties of the technology itself, both characteristics inscribed by the designer as well as characteristics of use as determined through previous use. The institutional conditions refer to the normative structures of the workplace, in which the users approach to the technology is structured by these norms of not only the organization but of the specific tasks that they conduct.

When we examine these three conditions in the ongoing process of emergent uses of a particular technology in an organization, we are able to gain perspective of not only what factors impact this emergent practice, but also what factors are being impacted by 
this new practice. This last component is where we as researchers can begin to understand what impact the adoption of the technology has had on different facets of the organization. In the context of adoption of emergent social media practices Orlikowski's model can serve as a general research framework to set the stage for an analysis of the emergent practices, but also the institutions - in form of norms, policies and strategies the organization has in place. While the properties of the technology itself are not our focus, it is important to recognize that when it comes to social media applications, users are operating in a fixed and pre-designed structure, but their innovative use in turn influences changes to the platforms themselves (see for example: [25])

In her structurational model, Orlikowski [22] explains the above process through a reciprocal relationship between social structures and the ongoing engagement of organizational members with technology. While being influenced by existing social structures, these engagements lead to the enactment of distinct forms of technology-in-practice, as social structures. As a result, people do not enact technology-in-practice in a vacuum since they are influenced by existing social structures enacted through previous actions. Figure 1 illustrates this recursive notion of technology adoption.

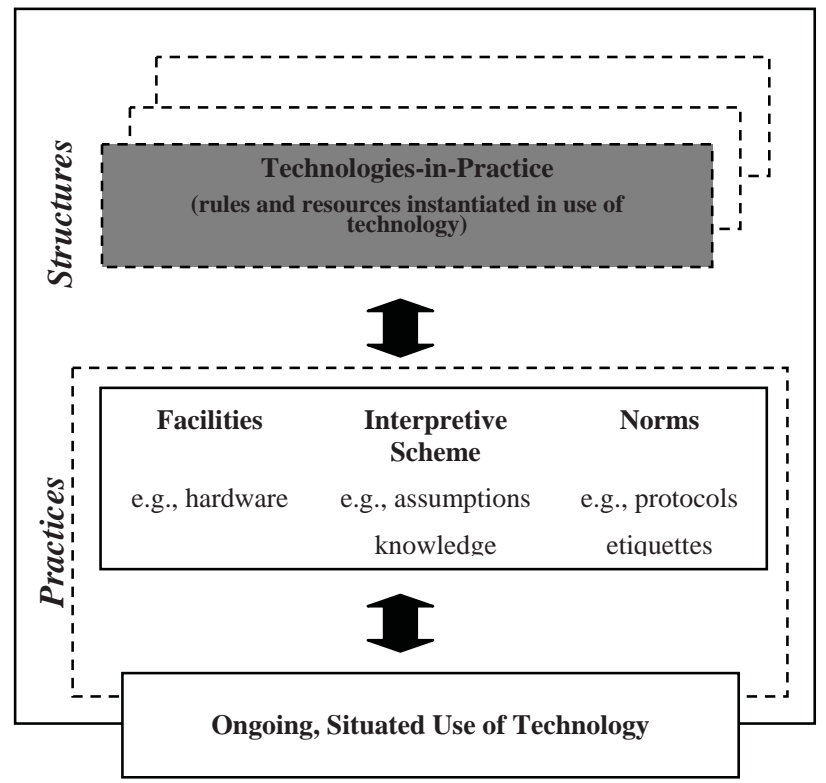

Figure 1. The duality between technology-in-practice and organizational practices, adopted from [22]

In summary, our analysis will begin by using Desanctis and Poole's attention to the detail of the social characteristics of the technology and the organization so as to provide a background description of the components of our investigation. Using Orlikowski's practice lens provides our analysis with a three step process whereby we examine the conditions that impact the adoption of the technology, how these conditions converge to form a practice of technology unique to the setting, and then how this practice recursively shapes the normative structure of the organization. While we do not use an ethnographic methodology to identify the emergent practice as Orlikowksi does, we believe that the stages of emergent practice described by Orlikowksi provide a valuable structure to the analysis of our interviews.

\section{RESEARCH DESIGN}

The research questions were pursued using an interpretive case study design, aiming at gaining new insights into innovative social behavior and generating theory based on perceptions of corporate social media strategists within this unique empirical context. Miles and Huberman's [19] approach for the design, collection, and analysis of qualitative data helped to guide the research framework and data inquiry. Following this approach, an initial code list based on the research framework was used to guide the inquiry. This framework then served as a basis for data collection and analysis.

\subsection{Data Collection}

The data collection goal was to compile a comprehensive sample of individuals across all industry sectors. Respondents for this study were selected through purposeful sampling [28] according to their professional roles in a multiple case study design. We recruited those individuals in each organization who filled the professional role of a social media director or who were responsible for the use of social media in their organization. We stopped recruiting additional respondents when we started getting similar responses and therefore had reached saturation in our sample. Our final pool of respondents consisted of 10 individuals, from 10 different industries, including management consulting, entertainment, food production, sports, news and publishing, etc.

We conducted semi-structured, open-ended interviews with these individuals, lasting between 45-90 minutes each and resulting in more than 160 pages of transcript. The interviews covered the following topics:

- Background information: The current position the respondent currently holds and their professional development before joining the current organization;

- Initial use of social media and top management involvement

- Standardization efforts: Formal vs. informal social media strategies and policies

- Tool adoption decision processes for internal and external use: resources, activities

- Day-to-day account administration: Schedules, responsibilities

- Formal metrics and informal success stories

- Adoption incentives and barriers

- Networked adoption: Formal and informal awareness network

- Value propositions: Outcomes, organizational and procedural changes, customer-driven innovation

\subsection{Data Analysis}

The analytic process was driven by the objective of making sense of the data by identifying recurring patterns. To this end, we followed the coding and analysis process described in Miles and Huberman [19]. All interviews were transcribed verbatim, and coded in a three-step process. During the first step, which Miles and Huberman refer to as open coding, the authors carefully reviewed the interview transcripts as they became available and attributed labels (or codes) to the corresponding passages. The authors then met as a team and discussed each label, resulting in a final code list. All interviews were then coded with the help of the 
qualitative research software package NVIVO 9 [20]. This form of coding allowed the authors to derive generalizable observations and to identify "repeatable regularities" in the data [14, p. 69].

A further step in the analysis was the construction of network matrices based on the interview partners' responses to their attention network and influencers [5]. These matrices were used to display the relationship between the respondents and the contacts they nominated as innovators they followed when it comes to acceptable social media use.

Throughout the data analysis process, the authors went back and forth between the data, the conceptual research framework and the literature to modify the initial findings accordingly.

\section{FINDINGS}

The primary goal of the data analysis of our interviews with social media strategists is to discover why and how innovative social media practices were adopted, what kind of influences the organization itself had on the adoption and in turn how the use of social media was reflected in the organizational context. The interviews with the corporate social media strategists highlight two different findings: First, social media in the corporate sector follows three distinct pathways, and second, social media strategists have an increased social awareness of other practice leads as well as information aggregators and influential technology bloggers. We discuss each finding starting with the pathways of adoption and their influence on the organization.

\subsection{Three pathways of social media use}

Social media adoption in the corporate sector follows three distinct pathways that each involve different types of social practices, either resulted in different types of norms, policies and social media strategies or evolved out existing strategies that were subsequently adopted and reflect the current state of acceptable use of social media as a technological and behavioral innovation in the corporate sector. These different pathways, as distinct social media-in-practice, lead to disparate organizational outcomes. We will discuss each pathway in the following paragraphs.

\subsubsection{Pathway 1: Early adopters and innovators}

The first pathway that emerged from the interviews includes social media practices of those organization that perceive themselves as product and practice innovators in their own industry. Their innovative social media-in-practice as a social structure entails outcomes such as the strive for increased transparency and accountability. These organizations are using social media to increase their visibility and are trying to accomplish this goal through increased interactions and conversations with their stakeholders.

One organization realized that there are two different ways of trying a new technology: One is creating policy before implementing it which can take some time and results in losing ground to other companies, as well as encouraging a more conservative approach whereby the key characteristics of the technology are not exploited; the other is, with the best interest of the company in mind, begin using the technology and then, through trial and error, create policy around the emergent use of social media as practice. This willingness to try reflects both a pro-adoption attitude towards new technology and, as one company mentioned, is reflected in the institutional norm of being

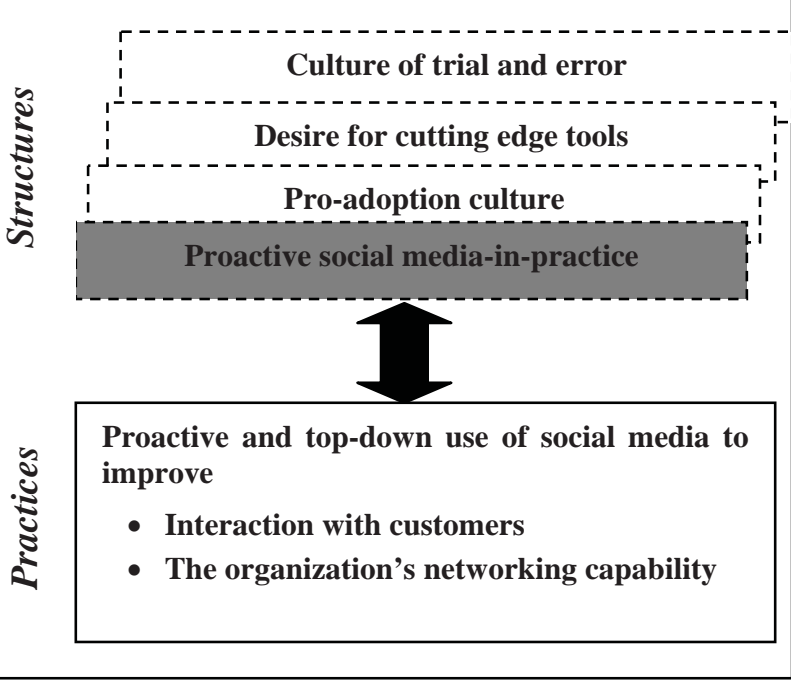

Figure 2. Proactive social media use in practice

a company that strives to be on the cutting edge. Speaking to the institutional norm of being an early adopter, as well as general pro adoption attitude of those who implemented social media technology, one respondent pointed out that:

"The organization has long desired to be a leader and a trailblazer as opposed to a follower and a late adopter. And so right away with the advent of Facebook and Twitter and the other social media channels out there, the organization jumped right on. There's a fast way to do things, and then there's the real fast way to do things, and they kind of took the latter, and to the point where I think you know the Twitter account and the Facebook account have been active for I want to say like 4 or 5 years now."

Another early adopter noted what we identified as two conditions that Orlikowski describes as impacting the adoption process. The respondent described how the policy developed around the use of social media was impacted by the workplace convention and institutional norms of keeping the best interests of the company in mind both from the stance of protecting its trade secrets (institutional norms) as well as promoting pro social interaction with current and potential clients (interpretive workplace convention):

"[The social media policy] basically, honestly says don't be stupid. I mean it does not say it that way, it is written a little bit differently. But, a lot of it is, you know, go out and do it, talk to folks, have those dialogues. We know from our standpoint, you would do it on the phone, you would do it face-to- face, you would do it over email, so, over fax, whatever you want, use it. So social is another way to have a great dialogue about the company, to share experiences. So, basically our policy is, be transparent, be open, make sure folks know who you are and what you are saying and where you are coming from. And do not say things you should not say that are proprietary or material of the company. Other than that, that is basically the core tenant of the policy. We have had that in place for about 4 and $1 / 2$ years now."

Based on the findings, we noted that early adopters tend to approach the use of social media from a risk-taking position whereby they recognize the value of the technology [8] and understand that they will be better off taking a trial-and-error approach rather than being too cautious. This willingness to take risks was reflected in both the conditions of institutional norms 
and interpretive conditions of workplace norms [22], whereby common sense business practice and concern for preserving the competitive advantage the company has guided the use of a new technology that did not yet have an official policy.

\subsubsection{Pathway 2: Internal mavericks}

The second pathway emerged as an internal practice. Social media in practice is used in a bottom-up manner. Internal champions who were searching for better and more effective ways to do their jobs or are willing to experiment with new technologies started their own local efforts, created anecdotal over time and then transported their success in form of a business case to their top management for after-the-fact approval. The bottomup social media-in-practice as a social structure entails outcomes that are reliant on value propositions provided through grassroots practice by individual internal thought leaders:

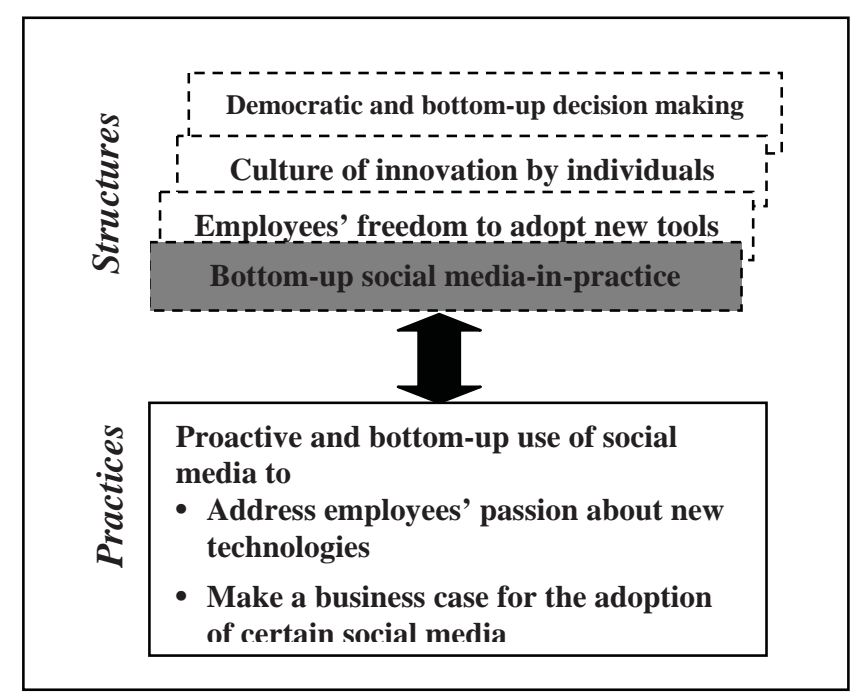

Figure 3. Bottom-up experimentation with social media-in-practice

Our findings showed us examples of approaching social media technology from an immediate understanding of where it was going to fit into the process of the overall organization. This realization was described as being acted on by internal players who make the case to upper management upon realizing the benefit for their particular department. As an example, for one company's recruiting division, the internal champion recognized that the college students that were the focus of their recruiting efforts were increasingly using social media technology, thus the need to be where the students were lead to initial experimentation with using social media. This interpretive condition based on workplace practice created a context through which the properties of social media technology and their value to the company could be understood. Regarding recruiting, the respondent stated that:

"There was a business case made that in order to do so properly, that we needed to be where our talent was in terms of looking at evaluating opportunities, and to get involved with social channels to be able to help with that campus outreach, or that overall talent acquisition outreach."

These internal champions - or what we like to call internal mavericks - were spearheading their own social media efforts and when the top management recognized their impact and the potenital that they created using social media, resources for additional capacity building were generated top down:

"So it almost happened very organically, just because of the nature of our company. [...] They are hiring people like me, and paying me a lot a money to do this. So, you know, each business unit is developing a roster of experts to get brought on, and then spearhead for the specific business needs."

As the respondents above point out, the outcomes of adopting social media technology eventually lead to an impact on both the structure and process of how the company operates, with new job positions created to have staff working full time on recruiting new hires through social media channels. A similar pathway was noted in an interview with another company in which members of the public relations department recognized that their company was being discussed and recognized on social media platforms without the company's direct involvement. Realizing a need to leverage this activity, a member of the public relations department made a presentation that made the case to upper management about getting the company involved in social media:

"I had put together a presentation talking about the existing social media footprint we had as a company, regardless of our participation in it, so there's over 500 [company name omitted] pages on Facebook, and there were 6,000 followers on Twitter. And, there was all this conversation going on in these major social media outlets that we weren't listening to or participating in or driving, and so I just kinda painted that picture to get people, more comfortable and to see the importance and relevance to the business of participating in those conversations. And, when I was pulled out to work on the team, I was given the focus of developing social media for [company name omitted]."

The perceived value of the technology [8], coupled with the interpretive condition of workplace convention [22] whereby public relations saw the value of social media technology as related to their work, resulted in both a structural and procedural change in the organization in the form of additional financial resources coupled with personnel decisions to increase capacity.

Other respondents that indicated social media technology's impact on the structure of the organization noted that changes occurred relating to both resource allocation as well as the eventual development of policy around the technology. One respondent pointed out that the company had been experimenting with platforms like Facebook and Twitter for over 5 years before they began developing policy. One reason for this lag in structural impact had to do with what the respondent saw as the perpetually changing features of social media:

"Just this off season, we're getting around to actually putting our social media strategies and policies on paper. So, that kind of tells you a little bit about how they have gotten into it, how the organization has kind of adopted it. It is kind of been, I don't want to say haphazard, I think that is a bad word, because I think that there is a lot a research that is gone into the different options that are out there. But, it is a quick world now, you know. The social media is a fast world and you have got to get on board. A lot a times there is just no time to sit down and create these strategies or these policies, and you just kinda have to make it up as you go along."

Relating to the allocation of resources, one company began experimenting with the use of blogs for different departments and 
found that, with surging popularity of the platform, the number of blogs being managed had reached a managerial cap in which the public relations team had to appeal to upper management for more resources to oversee the continued expansion of using social media technology:

\begin{abstract}
"The growth of our blog program had grown 300\% year over year. We did not have the bandwidth any longer, we could not even nudge the team, it was growing too fast, and it was becoming too much from the operations standpoint to be able to manage. So we basically had to say: we can not launch anymore blogs, we can not focus on any other social media projects, because we just do not have the resources right now to support it. So that is how we were able to start to receive some funding for the program itself."
\end{abstract}

\subsubsection{Pathway 3: Bandwagon jumpers:}

The third pathway includes all those organizations that are slower in adopting social media - but are still included in our sample as highly innovative social media practitioners. Their initial use lagged behind in time, but also followed their stakeholders as a response to their customers' existing use of social media. This imitative social media-in-practice as a social structure entails goals to increase what one of our interview partners called the "coolness" factor - showing that their company is also using cutting edge tools that their customers are involved in. Others in this category mostly perceive the value of social media in a reactionary way and use it as additional channels to "set the record straight". That means they are mostly trying to populate social media channels with their side of a story to counterbalance existing rumors or press coverage.

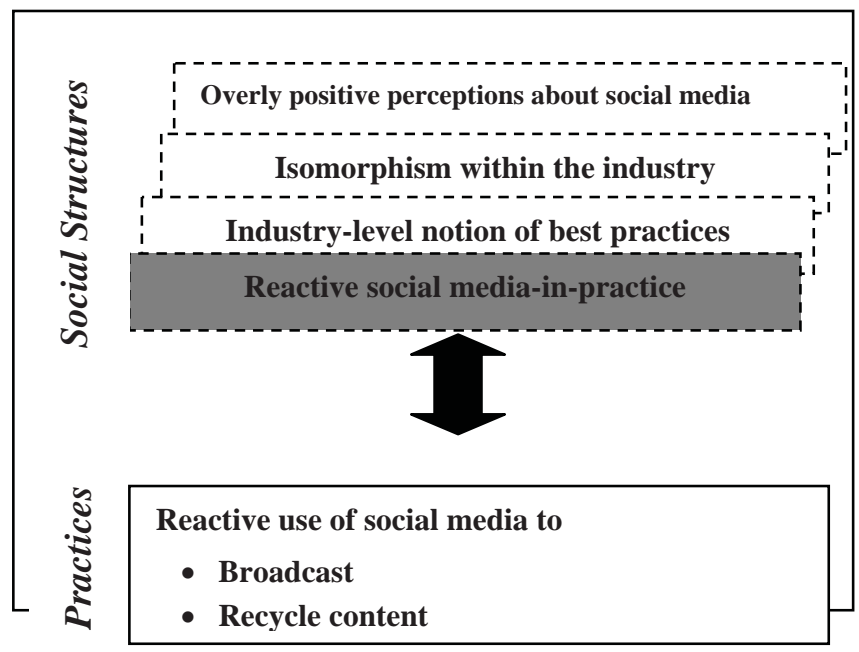

Figure 4. Reactive social media use in practice

Several organizations included in our sample are taking on a passive and reactive approach in that the adoption process is mostly driven by external forces. In this approach, organizational leaders jump onto the bandwagon of adoption based on how many other organizations have adopted social media [1]. Organizational scholars dubbed this tendency isomorphism [9] where clusters of organizations (i.e. competing companies, their suppliers, and professional and trade associations) tend to develop similar technology adoption behaviours [2]. These organizations therefore do not sufficiently evaluate internal needs for social media, and they may lay out too broad and often unrealistic objectives. One social media strategist explained his company reactive adoption practice:

"My understanding is that our company wanted to get into social [media]. Well, all of the company wanted to get into social. And they wanted to make sure they did it right. And they looked for experts in the field, obviously they wanted to make a big splash after all the government issues that they had with all the bankruptcy and everything."

Influenced by hype and a set of best practices from different industries, the organizations within this group hope to achieve several objectives without fully assessing their own organizational context and needs. These hypes create overly positive perceptions about organizational opportunities for the exploitation of social media. Social media vendors and the inter-organizational network of social media evangelists and consultants often fuel these perceptions. Our data indicate that organizational leaders and media strategists are learning from influential technology bloggers such as TechCrunch, Mashable, Chris Brogan, Brian Solis, or information aggregators such as the Huffington Post. They are also typically members of various social media communities such as the Social Media Business Council and the Silicon Valley Social Media Practitioner Group. The following network diagram shows who is paying attention to whose social media practices. We derived the connections between the nodes from our interviews by asking the social media directors who they think is using social media in the best possible way. Larger nodes highlight our interview partners [company names are omitted]; smaller nodes indicate the organizations and influencers they are paying attention to when it comes to adoption of social media practices:

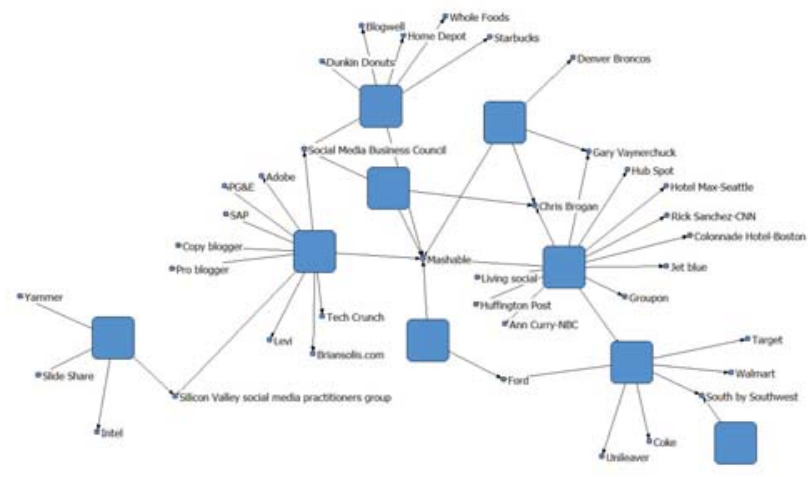

Figure 5. Social media awareness network

This attention network indicates that the adoption process is primarily driven by external forces: this last group of social media users lack intra- and entrepreneurial initiatives for the use of social media as a new vehicle for knowledge sharing, organizing, and interacting with different stakeholders. Therefore, they often employ social media similar to old communication tools, glossing over the unique nature and affordance of social media. For example, a senior manager makes clear that they use Facebook more or less like the corporation's website, with the traditional mindset of broadcasting information in a one-way manner, but adding a few more media contents than on their homepage: 


\begin{abstract}
"...[regarding]Facebook, the hope is to actually encourage sharing of information to be able to do so in a way that is a little more informal than we are on our dot com [the company's website] or other areas. We're starting to incorporate more media into that: video, photography, things of that nature."
\end{abstract}

Overlooking the interactive affordances of social media, these organizations may also employ these tools to recycle content they have already published via other channels. Explaining this strategy, a marketing manager stated:

"Yes, we tend to look at Facebook; we post back to there. It may be an article that someone's quoted in, it could possibly be a press release. We push out a lot of research reports, and white papers and such, so a lot of it will kind of link back to those. There are programs that we support in other media. We will point back to some of that multimedia content that is being pushed out. Our initial goal has been really to expand, extend, and amplify content that's already being produced for other marketing channels."

\section{DISCUSSION AND CONCLUSION}

There has been increased attention on the use of social media in all sectors, especially in the corporate sector to foster relationships to customers and to generally have a presence where the customers are. The pathways that organizations chose to accomplish this goal are especially interesting given that each organization has different perceptions of the usefulness of their own activities on social media channels. Existing standard practices, such as a static information website do not allow the same interactive possibilities that social media tools provide. It is therefore interesting to investigate how and why corporations are adopting social media practices, what their adoption pathways are, and how organizational policies and norms conform to the observed social structures.

In our research we followed Orlikowki's model to understand the possible duality between technology-in-practice and organizational practices. We discovered that Orlikowski's model helped us to frame the general issue. In addition, our findings show that in some cases especially innovative social media practices have a reflexive feedback mechanism: The use of social media in practice has an impact on existing strategies and policies that were in turn rewritten to reflect the innovative social structure. In other cases, organizations operated outside the existing strategies and norms and innovative engagements with social media lead to new sets of policies and strategies. Moreover, in the third pathway, the use of social media by a certain group of people has made a case for senior managers, leading them to enact policies that endorse the use of social media and the necessary capacities and resources.

Our findings show that informal, bottom-up and mostly unsanctioned early experimentations lead to new technology practices, that evolve over a period of time until they become part of the accepted use policies of the organizations included in our sample. The emergent practices create the need for new structures, such as organizational capacity in form of formal positions (e.g, the newly created position of a social media director). In order to create a business case for top management support, technology practices had to evolve into business cases that showed tangible impact on the organization - and then top down decision followed. In comparison to other types of technology adoption decisions, such as a company-wide email system for example, social media practices emerged based on individual innovators in small pockets of the organizations - but practices were not adopted based on a unified decision. Finally, our findings add to the existing research on technology adoptin in so far as they show that norms, such as social media strategies or policies followed early practices and structures. Again, opposite to other forms of technology use, norms formed out of emergent practices instead of set standards of the adopted technology or a top down decision.

Our research is certainly limited by the relatively small sample size. Assessing and testing our findings in a large-scale online survey can bring additional clarity and help to verify the adoption pathways that emerged from our sample. Additional research is necessary to gain a deeper understanding into questions we haven't addressed in our research, but arise as a result of our findings. For instance, going back to the social awareness network among organizations in our sample illustrated in figure 5, it would be interesting to trace similarities of social media practices among organizations that are paying attention to the same influencers. Is it for example possible to show a standardization among organizations who pay attention to the same social media trendsetters, and as a result copy each others' behavior? And is it possible to discover sector- or industry-wide normalization processes that are adopted as new standards of communication with customers and build a new form of customer service over time?

\section{REFERENCES}

[1] Abrahamson, E. and Rosenkopf, L., 1993. Institutional and competitive bandwagons: Using mathematical modeling as a tool to explore innovation diffusion. Academy of management review, 487-517.

[2] Avgerou, C., 2002. The socio-technical nature of information systems innovation. In Information systems and global diversity, C. Avgerou Ed. Oxford University Press, USA.

[3] Barnes, N., G., 2010. The Fortune 500 and Social Media: A Longitudinal Study of Blogging, Twitter and Facebook Usage by America's Largest Companies The University of Massachusetts Dartmouth Center for Marketing Research http://www.umassd.edu/media/umassdartmouth/cmr/studiesa ndresearch/2010F500Final.pdf.

[4] Barnes, N., G. and Lescault, A., 2010. Social Media Adoption Soars as Higher-Ed Experiments and Reevaluates Its Use of New Communications Tools. The University of Massachusetts Dartmouth Center for Marketing Research http://www.umassd.edu/media/umassdartmouth/cmr/studiesa ndresearch/higherEd.pdf.

[5] Borgatti, S.P., Everett, M.G., and Freeman, L.C., 2002. UCINET 6 for Windows: Software for social network analysis, Version 6.102. Harvard, Massachusetts: Analytic Technologies.

[6] Bourdieu, P., 1977. Outline of a Theory of Practice. Cambridge University Press, Cambridge, UK.

[7] DeLuca, D., Gasson, S., and Kock, N., 2006. Adaptations that virtual teams make so that complex tasks can be performed using simple e-collaboration technologies. International Journal of e-Collaboration 2, 3, 65-91.

[8] DeSanctis, G. and Poole, M.S., 1994. Capturing the complexity in advanced technology use: Adaptive structuration theory. Organization science 5, 2, 121-147.

[9] DiMaggio, P.J. and Powell, W.W., 1983. The iron cage revisited: Institutional isomorphism and collective rationality 
in organizational fields. American sociological review, 147160.

[10] George, B., 2010. How Social Networking Has Changed Business. HBR Blog Network http://blogs.hbr.org/hbsfaculty/2010/12/how-socialnetworking-has-chan.html, Dec 23.

[11] Giddens, A., 1979. Central problems in social theory: Action, structure, and contradiction in social analysis. University of California Press, Berkeley.

[12] Hinchcliffe, D., 2011. Social business holds steady gap behind consumer social media. ZDNet http://www.zdnet.com/blog/hinchcliffe/social-business-holdssteady-gap-behind-consumer-social-media/1695, Aug 27.

[13] Jarrahi, M.H., 2010. A structurational analysis of how course management systems are used in practice. Behaviour and Information Technology 29, 3, 257-275.

[14] Kaplan, A., 1964. The conduct of inquiry; methodology for behavioral science. Chandler Pub. C, San Fransisco.

[15] Keitt, T., Brown, M., and Dang, J., 2011. The State Of Collaboration Software Implementations. Forester Research http://www.forrester.com/rb/Research/state_of_collaboratio n_software_implementations_2011/q/id/58709/t/2, March 21.

[16] Mackrell, D., Kerr, D., and Von Hellens, L., 2009. A qualitative case study of the adoption and use of an agricultural decision support system in the Australian cotton industry: The socio-technical view. Decision Support Systems 47, 2, 143-153.

[17] Madden, M. and Zickuhr, K., 2011. 65\% of online adults use social networking sites, Report published by Pew Internet \& American Life Project. available online: http://pewinternet.org/Reports/2011/Social-NetworkingSites.aspx.

[18] McAfee, A., 2006. ENTERPRISE 2.0. MIT Sloan management review 47, 3, 21.

[19] Miles, M.B. and Huberman, A.M., 1994. Qualitative data analysis: An expanded sourcebook. Sage Pubs, Thousand Oaks.
[20] NVivo, 2011. NVivo qualitative data analysis software (Version 9). Melbourne: QSR International Pty Ltd.

[21] O'Reilly, T., 2005. What Is Web 2.0: Design Patterns and Business Models for the Next Generation of Software. Available online:

http://www.oreillynet.com/pub/a/oreilly/tim/news/2005/09/30 /what-is-web-20.html.

[22] Orlikowski, W.J., 2000. Using technology and constituting structures: A practice lens for studying technology in organizations. Organization science 11, 4, 404-428.

[23] Rodriguez, C. and Pozzebon, M., 2011. Understanding managerial behaviour during initial steps of a clinical information system adoption. BMC Medical Informatics and Decision Making 11, 1, 42.

[24] Skeels, M.M. and Grudin, J., 2009. When social networks cross boundaries: a case study of workplace use of facebook and linkedin. In Proceedings of the GROUP'09 (Sanibel Island, Florida,2009), ACM New York, NY, USA, 95-104.

[25] Spencer, W., 2011. Facebook Reacts to Privacy Backslash as Competition Gears Up. Available online: http://www.techfaq.com/facebook-reacts-to-privacy-backslash-ascompetition-gears-up.html.

[26] Steinfield, C., DiMicco, J.M., Ellison, N.B., and Lampe, C., 2009. Bowling online: social networking and social capital within the organization. In Proceedings of the The fourth international conference on Communities and technologies (2009), ACM, 245-254.

[27] Wu, A., DiMicco, J.M., and Millen, D.R., 2010. Detecting Professional versus Personal Closeness Using an Enterprise Social Network Site. In Proceedings of the CHI 2010 (Atlanta, Georgia2010).

[28] Yin, R., 2009. Case study research: Design and methods. Sage publications, Thousand Oaks. 